\title{
Multi-Criteria Analysis for the Best Location Selection in Chittagong city Area, Bangladesh
}

\author{
Nurul Absar \\ Assistant professor \\ Department of Computer \\ Science and Engineering. \\ BGC Trust University \\ Bangladesh
}

\author{
Abhijit Pathak \\ Lecturer \\ Department of Computer \\ Science and Engineering. \\ BGC Trust University \\ Bangladesh
}

\author{
Md. Abbas Uddin \\ Graduated with B.Sc (Hons) \\ degree from the Department of \\ Computer Science and \\ Engineering.BGC Trust \\ University \\ Bangladesh
}

\begin{abstract}
Multi-criteria analysis (MCA) provides a more reasonable and scientific way in optimum area selection issue. The paper aimed to select the best area in Chittagong city, Bangladesh. A decision is the result of a comparison of one or more alternatives with respect to one or more criteria that we considered relevant for the task at hand. Multi-criteria evaluation is primarily concerned with how to combine the information from several criteria to form a single index of evaluation. Multi-criteria analysis can contribute to the evaluation of a programmed or a policy through the appraisal of its impacts with regards to several criteria. As a result the optimum area of multi criteria should be considered many criteria to select best area so that any client to get owns their facility. The project work has been done based on some development area of Chittagong city. The weights for multicriteria analysis are obtained from the factor criteria. For selection of best area there were a lot of elements that should be taken into consideration. These factors are public Hospital, Public College, Madrasha, School, Proximity to airport, Fire service, Transportations, Market, Police station, Sea beach, Number of Park, Number of Playground, House rent, Availability of gas facility. So the people who want to live in this area which is contain own their facility in Chittagong city, they can search their best place or good location by this project. People must save their time to get a sweet able location by this project.
\end{abstract}

\section{General Terms}

Multi-Criteria Analysis (MCA)

\section{Keywords}

Multi-Criteria Analysis (MCA), Location planning, Best Location Selection, Analytic Hierarchy Process (AHP), Decision making, The Chittagong.

\section{INTRODUCTION}

Chittagong is the Second Largest city, Prime Sea Port and the heart of all commercial and business activities in Bangladesh. Chittagong city is situated on the bank of Kharnaphuly River. The Latitude and Longitude of Chittagong city is 22.330391 and 91.82518 respectively. In the last few years, the Chittagong area in Bangladesh is developed by many residence areas. The limited resources and infrastructure, it has presented a wide of range problems which is the best area for client to live for comfortable in these areas. It has become one of the most challenging phenomena all around the world during the beginning of twenty-first century. Therefore, multiple criteria analysis (MCA) is a framework for evaluating decision options against multiple criteria.
Numerous techniques for solving an MCA problem are available. [1].

Whatever the definition, it is generally assumed in MCA that the decision maker has to choose among several options or alternatives. The set of alternatives is the collection of all alternatives. Selecting an alternative among this set depends on many characteristics, often contradictory, called criteria. Accordingly, the decision maker will generally have to be contented with a compromising solution [2].

Multi-criteria evaluation is primarily concerned with how to combine the information from

several criteria to form a single index of evaluation. Multicriteria analysis is undertaken to make a comparative assessment between projects or heterogeneous measures. In the evaluation field, multi-criteria analysis is usually an exact evaluation tool, and is particularly used for the examination of the intervention's strategic choices. In ex post evaluations, multi-criteria analysis can contribute to the evaluation of a programme or a policy through the appraisal of its impacts with regards to several criteria.

Owing to the successful development in the recent 50 years, Multi Criteria analysis has been widely used in many aspects for example, the resource management which can make sure the sources is used in a reasonable way Multi-criteria analysis (MCA) also plays an important role in urban site selection for finding the best locations and optimizing urban structures. According to the Multi-criteria analysis, a manual which was published by the Communities and Local Government of Great Britain, Multi-criteria analysis (MCA) is defined as an approach which explicitly shows all options and their contributions with the help of which the decision makers can judge them [3]. During the 1970s and at the beginning of the 1980 s a great number of multi criteria methods were developed and used for different policy purposes in different contexts.

\subsection{Scope of the Project}

When people need to move from one place to another places, they want to get some specific facilities which directly involved with human life so that they felling comfortable this palace. But it is difficult any people to decide which place is very good place from other place and available all facilities which they need. For this they have to consider many factors of that location. So we have tried to create a system so that people could find their best area and get all facilities. This system was made by multi criteria analysis method. 


\subsubsection{Importance of Multi criteria analysis:}

The Analyses should be limited to the comparison of straightforward activities, and conducted with a limited number of criteria. Multi-criteria analysis is based on the rating. Criteria should be defined by rules recognized and accepted by all, prior to the undertaking of the analysis. Criteria should be unique, although the criteria for the expected salary and the level of experience are likely to be related. They should be coherent: Some criteria may have such importance that they have to be singled out. This is the case for criteria determined by a veto threshold (some of them can be imposed by the regulation). Multiple Criteria Analysis provides an appropriate tool for addressing some specific useful attributes of MCA are outlined below.

1. Capability to accommodate multiple criteria in the analysis.

2. MCA can work with mixed data and the analysis need not be data intensive. It allows for the incorporation of both qualitative and quantitative information.

3. It allows the direct involvement of multiple experts, interest groups and stakeholders.

4. Analysis is transparent to participants.

5. MCA includes mechanisms for feedback concerning the consistency of the judgments made.

\subsubsection{What is it used for?}

There are numerous descriptions of the MCA decision making process [4] and preference modeling [5]. Applications of MCA generally include [1]:

1. Choose decision options.

2. Choose evaluation criteria.

3. Obtain performance measures and fill in the EM.

4. Transform into commensurate units (this depends on the type of MCA technique being applied). This may require decision maker preference inputs.

5. Weight the criteria. This is heavily dependent on decision maker preferences.

6. Rank or score the options.

7. Perform sensitivity analysis (weights, performance measures, techniques)

8. Make a decision

\subsection{Aims of the Project}

This study intends to select a comfortable area for client in Chittagong Metropolitan area by using Multi-Criteria Analysis (MCA). Firstly, this study performs two necessity tests and two sensitivity tests on the factor criteria. After that, the client areas with maximum values are selected. Finally, taking the optimal place for client is decided.

\subsection{Methodology of multi criteria evaluation}

Location planning for urban distribution centers is vital in minimizing traffic congestion arising from goods movement in urban areas. In recent years, transport activity has grown tremendously and this has undoubtedly affected the travel and living conditions in urban areas. Considering this growth in the number of urban freight movements and their negative impacts on city residents and the environment, municipal administrations are implementing sustainable freight regulations like restricted delivery timing, dedicated delivery zones, congestion charging etc[6]. We have considered the criteria of location firstly, So that we can understand which place is best area in city. The criteria for the best area were Proximity to main road, health facilities, education facilities, play ground, Shopping mall and so on. For those criteria we have assigned value and count standraizaration score from the assign values. Finally we have count total value and the maximum total is best result.

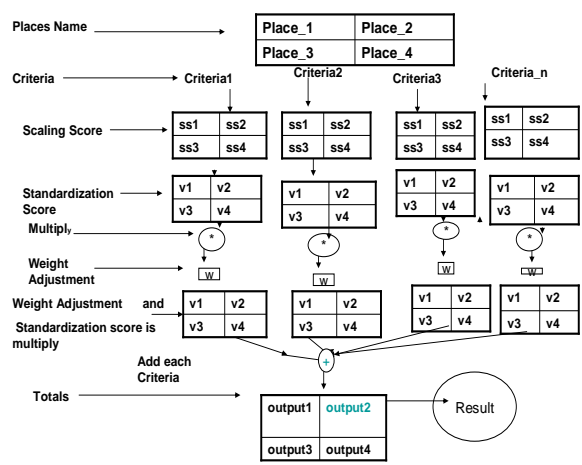

Figure 1.1: Architecture of Multi criteria evaluation

\subsection{System Requirements}

1. Windows XP/7/Vista/Linux.

2. Desktop Computer/Laptop Computer.

3. NeatBeans Editor Software.

4. Wamp server (Sql).

\section{DESCRIPTION OF THE STUDY AREA}

Bangladesh is a small country. It has eight divisions those are Dhaka, Chittagong, Rajshahi, Khulna, Barisal, Shylet, Rangpur and Mymansing .But Chittagong division is the sound largest city in Bangladesh. The total area of the city is $168.07 \mathrm{~km} 2$ (64.89 sq. mi). The Coordinates of the Chittagong is $22^{\circ} 22^{\prime} 0^{\prime \prime} \mathrm{N} 91^{\circ} 48^{\prime} 0^{\prime \prime} \mathrm{E}$. Recently many area of Chittagong are developed with modern facilities .People want to live in the area which is contain own their facility. It is tedious and time consuming to select a best area to live. For this we have studied only Chittagong area using Graphical information System (GIS) in Chittagong to select the best area. The location map of Chittagong city are given below 


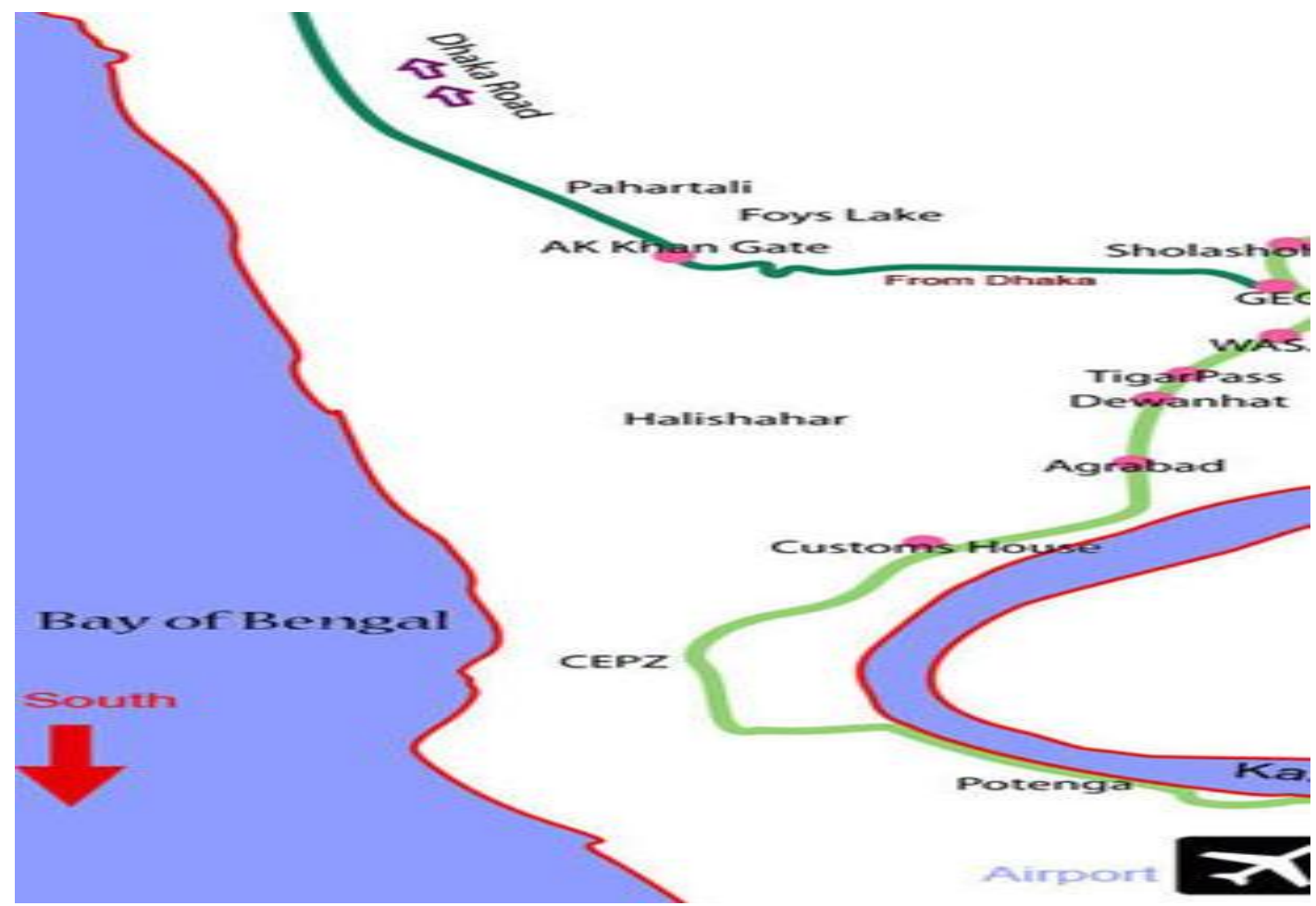

Figure 2: The location of Chittagong city area.

\subsection{Algorithm of Multi Criteria evaluation Step1.}

Selection of criteria.

\section{Step2}

Standardization of criterion scores.

\section{Step3}

Allocation of weights. Weights are allocated which reflect the relative importance of data may be expressed as 0.8 .

\section{Step4}

Applying the Multi Criteria Evaluation algorithm. A Multi Criteria Evaluation algorithm may then multiply this starndized scores by the weights for each of the data layer and sum these to allocate a score to each pixed on the outmap.The map produced will be a surface with values ranging from 0 to 1 .

\subsection{Criteria determination}

Analytic Hierarchy Process (AHP) is developed by Saaty (1980) and then it is used widely as an efficient multi-criteria decision making (MCDM) method for ranking alternatives [7]. AHP is based on three principles: structure of the model; comparative judgment of the alternatives and the criteria; synthesis of the priorities [8] one of the main advantages of this method is the relative ease with which it handles multiple criteria. In addition to this, AHP is easier to understand and it can effectively handle both qualitative and quantitative data. The use of AHP does not involve cumbersome mathematics [9]. Because of these reasons AHP has been applied many areas such as personal, social, manufacturing sector, political, engineering, education, industry, government and others which include sports, management, etc. [10]. AHP can efficiently be integrated with other methods like mathematical programming, quality functions deployment, meta-heuristics, SWOT analysis and data envelopment analysis [11].

The main advantage of this procedure is its simplicity since the weighting of criteria takes place before the utilizations of the model, so that once the weighting of the different criteria has been established, the analyst may proceed towards the solution of the problem. In discrete MCDA problems, there are several procedures aiming at obtaining the decisionmaker's priorities in the form of weights. For the selection of resident area in Chittagong city there were a lot of elements that should be taken into consideration. According to various factors there were main aspects to be considered. Some of them are given below

\subsubsection{Park, Playground and beaches:}

Park and play ground around the residential area is more recreational zone for good health and mode of relaxations. The Chittagong Division is known for its rich biodiversity. Over 2000 of Bangladesh's 6000 flowering plants grow in the region. Its hills and jungles are laden with waterfalls, fast flowing river streams and elephant reserves. St. Martin's Island, within the Chittagong Division, is the only coral island in the country. The fishing port of Cox's Bazaar is home to one of the world's longest natural beaches. The popular recreational zone of Chittagong are Chittagong Ethnological Museum, Heritage Park or mini Bangladesh, Foy's Lake, Patenga Sea beach, Lal Dighi,War Cemetery Chittagong Bangladesh,Chittagong Zoo and Court Building, Khoiyachora waterfall, Sitakunda Eco Park Bangladesh, Ethnological Museum of Chittagong, Halda River

\subsubsection{Real Estate Value:}

Since buying a home is the single largest investment we will probably ever make, we need to seriously consider this factor. With real estate in a constant state of flux, it's important to research current home prices, the length of time homes are for sale, the resale values of homes, and probable long-term value estimates. 


\subsubsection{Crime Rates and Statistics}

No one wants to live in a high-crime area, but that doesn't mean that everyone can live in a Utopian society where crime never happens. By researching the crime rates and statistics for various areas, you can learn more about the safety of a town or neighborhood. If you have already decided where you want to live, stop by the local police stations to discuss your new neighborhood. The police will be happy to discuss any concerns you have about the area. I can also check out Crime Reports, which lets you review crime statistics for different neighborhoods.

\subsubsection{Education System}

Good education is essential to setting up children to better handle the rest of their lives, so the importance of good schools cannot be overstated. Parents chose the town where we lived because of the public school; College, Madrasha and University are less distance from the area.

\subsubsection{Healthcare Facilities}

Healthcare facilities are important at any stage in life, but they are especially relevant if you have children or if you are nearing retirement age. Easy access to good healthcare can increase your quality of life exponentially, so be on the lookout for towns and cities with good hospitals and medical schools. Often, there will be a correlation between these areas and the quality of the healthcare.

\subsubsection{Employment Opportunities}

Employment opportunities vary from state to state and city to city, so spend some time researching the job markets in different areas of the country. Start by analyzing quality employment opportunities within your industry, and then determine where the highest concentration of these jobs is located.

\subsubsection{Proximity to an Airport}

If you travel a lot, you may need to live within close proximity of an airport. If you live more than an hour away from the closest airport, traveling to and from the airport can become very time-consuming and expensive. If you spend a healthy amount of time traveling, definitely consider the distance to the airport.

\subsubsection{Safety}

It is the part of human rights. For this we select the safety area which contains fire service, Police stations and so on.

Table1: Factors Name with Constraint area.

\begin{tabular}{|c|c|}
\hline Factors Name & Constraint area \\
\hline Park, Playground, & In resident areas are number of park, playground and so on. \\
\hline Real State Value & Minimum Cost. \\
\hline $\begin{array}{c}\text { Public facilities (Hospitals, College, } \\
\text { School, Madrasha, Fire service, Bus } \\
\text { station, University, Police Stations }\end{array}$ & $\begin{array}{c}\text { Public hospital, College, School, Madrasha, way, Fire Service, Police } \\
\text { Stations as well as the areas around within 10 meters. }\end{array}$ \\
\hline Crime Rate & Low, Medium, High crimes statists in these areas. \\
\hline Gas Facility & Yes or No? \\
\hline Seal Beach, Airport & Main road and the areas around within 10 meters. \\
\hline Main road & \\
\hline
\end{tabular}

\subsection{Weight Allocation for best area}

Allocating the weight for this project to considered the best area for client which is consists of Employment Opportunities, Proximity to an Airport, Crime Rates and Statistics, Real Estate Value, Healthcare Facilities, Educational such as (Public school, College, Madrasha) is depend distance value of Minimum 10 meters, Proximity to an Airport data represent depends on distance values (Near or Far).If needed Near then Near $=0-50$ Kilometers and Far $=50$ 100 Kilometers. Crime Rates values are present Low,
Medium, High. The criteria value of Gas facility is represented data Yes Or No. If we select any area and gas facility have in these area then we represent data Yes=1 and No $=0$. The factor of Shopping mall or market score depends on distance from these areas. The distance of minimum value for shopping mall or market is 10 Kilometers as well as these areas. These criteria can be representing in many categories.

Table 2: Criteria's Name corresponding Categories.

\begin{tabular}{|l|l|}
\hline Category & \multicolumn{1}{|c|}{ Criteria's Name } \\
\hline A & $\begin{array}{l}\text { Pubic (School, College, Madrasha, Hospital) Police Station, Fire Service, Main Road, } \\
\text { Shopping mall or Market, University and so on. }\end{array}$ \\
\hline B & Seal Beach and Airport. \\
\hline C & Gas facility \\
\hline
\end{tabular}




\begin{tabular}{|l|l|}
\hline D & House rent \\
\hline E & Park, Playground \\
\hline F & Crime Statists \\
\hline
\end{tabular}

Table 3: Weighted values for Category A.

\begin{tabular}{|c|c|c|}
\hline Criteria's name & $\begin{array}{c}\text { Distance from } \\
\text { these areas }\end{array}$ & Assign Weight value \\
\hline $\begin{array}{c}\text { Pubic(School, College, Madrasha, Hospital) } \\
\text { Police Station, Fire Service, Main Road, } \\
\text { Shopping mall or Market, University and so on. }\end{array}$ & $\begin{array}{c}\text { Distance value from } \\
\text { area is } \\
1-10 \text { meters }\end{array}$ & 0.9 \\
\cline { 2 - 3 } & $10-20$ meters & 0.8 \\
\cline { 2 - 3 } & $20-30$ meters & 0.7 \\
\cline { 2 - 3 } & $30-40$ meters & 0.6 \\
\cline { 2 - 3 } & $40-50$ meters & 0.5 \\
\cline { 2 - 3 } & $50-60$ meters & 0.4 \\
\cline { 2 - 3 } & $60-70$ meters & 0.3 \\
\cline { 2 - 3 } & $70-80$ meters & 0.2 \\
\cline { 2 - 3 } & $80-90$ meters & 0.1 \\
\hline
\end{tabular}

Table 4: Weight value for Category $B$.

\begin{tabular}{|l|l|l|}
\hline Criteria's name & Distance value from these areas & Assign weight value \\
\hline Sea Beach, Airport & $0-50$ kilometers & 0.9 \\
\cline { 2 - 3 } & $50-100$ kilometers & 0.1 \\
\hline
\end{tabular}

Table 5: Weight value for Category $C$.

\begin{tabular}{|l|c|l|}
\hline Criteria's name & Availability these areas & Assign weight value \\
\hline Gas facility & Yes & 0.9 \\
\cline { 2 - 3 } & No & 0.1 \\
\hline
\end{tabular}

Table 6: Weight value for Category $D$.

\begin{tabular}{|l|l|l|}
\hline Criteria's name & Rent in these areas & Assign weight value \\
\hline \multirow{3}{*}{ House rent } & Minimum cost 5000 taka & $0.5-0.9$ \\
\cline { 2 - 3 } & Otherwise & $0.1-0.5$ \\
& & \\
\hline
\end{tabular}

Table7: Weight value for Category $E$.

\begin{tabular}{|c|c|c|}
\hline Criteria's name & Depends number include these areas & Assign weight value \\
\hline Park \& Playground & The maximum number is best priority. & 0.9 \\
\cline { 2 - 3 } & The minimum number is low priority. & 0.1 \\
\hline
\end{tabular}


Table 8: Weight value for Category $F$.

\begin{tabular}{|l|l|l|}
\hline Criteria's name & Crime area & Assign weight value \\
\hline Crime rate & Low (1) & $0.1-0.3$ \\
\cline { 2 - 3 } & Medium (2) & $0.3-0.6$ \\
\cline { 2 - 3 } & High (3) & $0.6-0.9$ \\
\hline
\end{tabular}

\section{DESIGN AND IMPLEMENTATION}

\subsection{Login Page}

Login page contain user name and password, so that user can login this project after registration. When users view the main page then they complete their registrations using Username \&
Password after successful completion they can login just use the login button

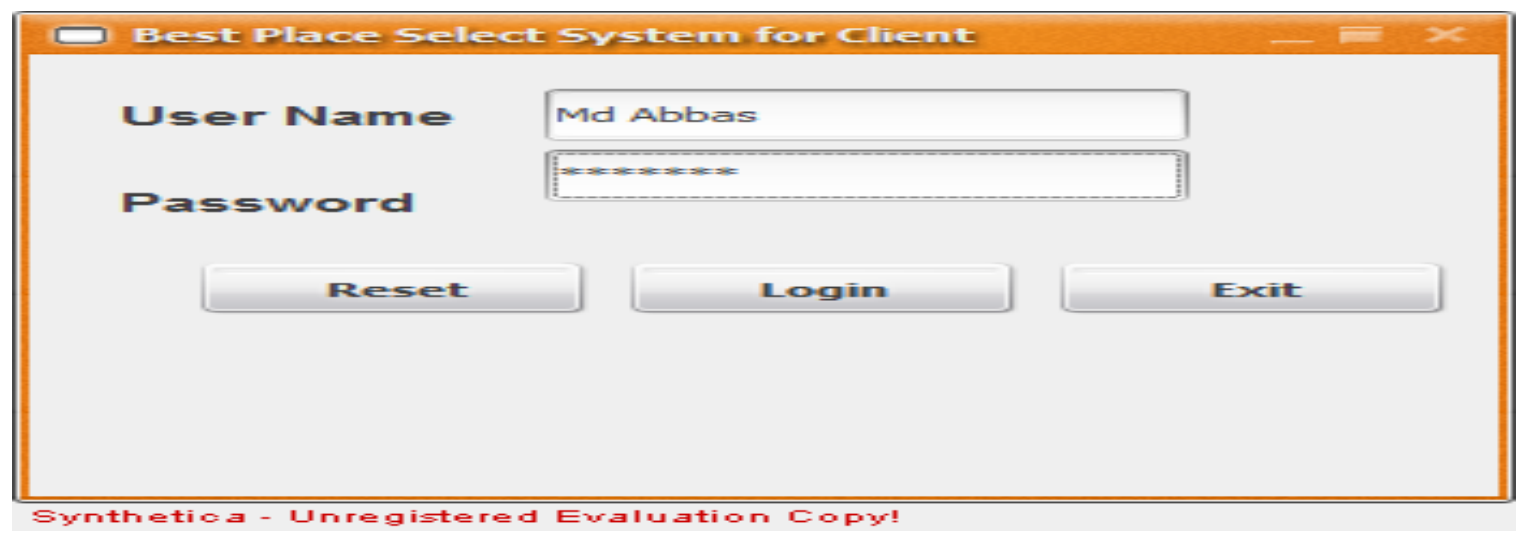

Figure 3: Snap shot of Interface for login page.

\subsection{Main page}

Main page is the page which contains Insert Location, Edit Location, Delete Location, Show Location Rating, Final
Location Search, Developer Information, Helper Information Registration, Exit and Back. By this page any user can link each page of this project.

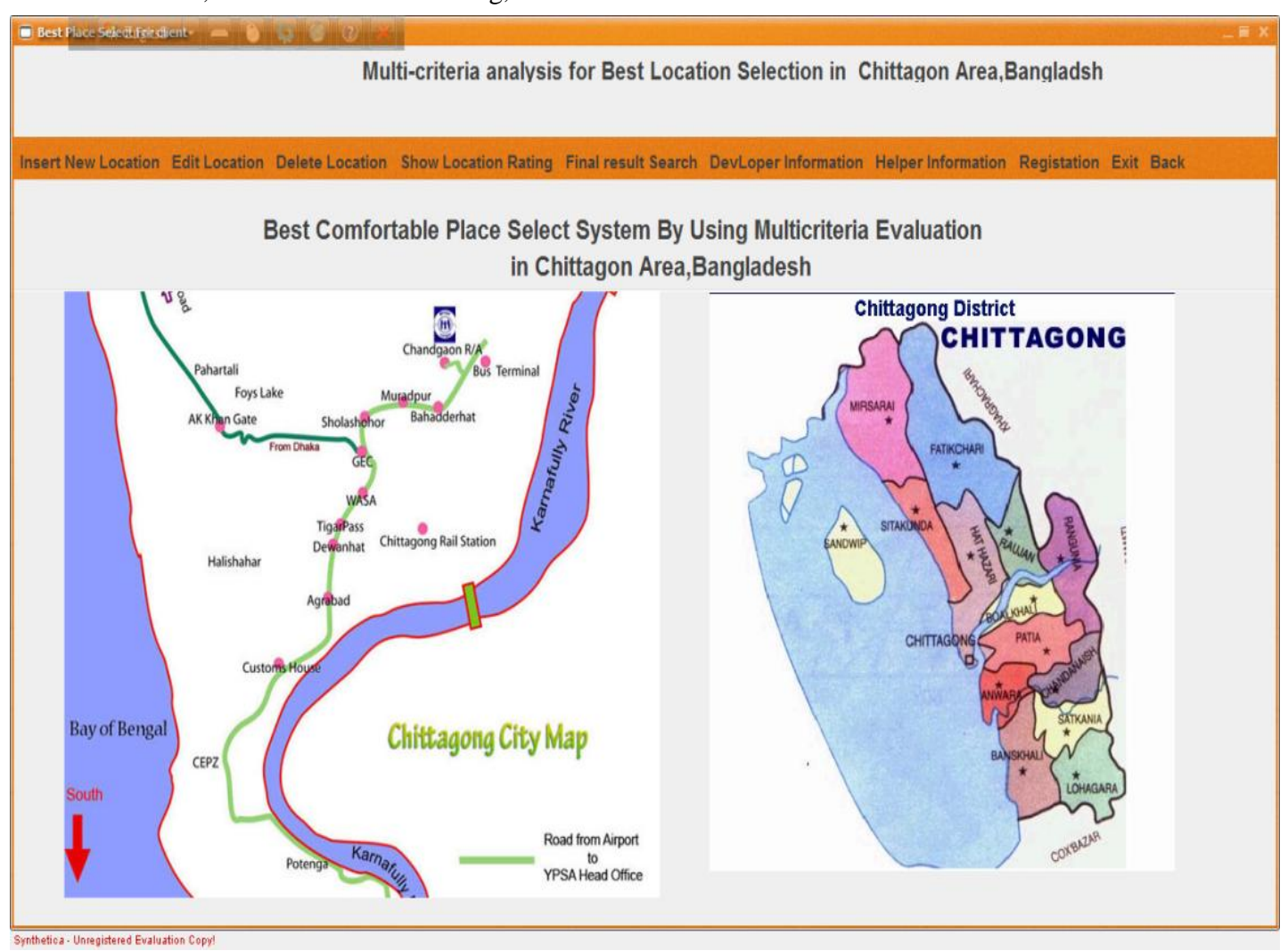

Figure 4: Main page of this project. 


\subsection{Rating Insert Page}

Rating Insert Page is the page where an admin can insert data in database table. It is used for entry rating in database table. By this page we stored data.

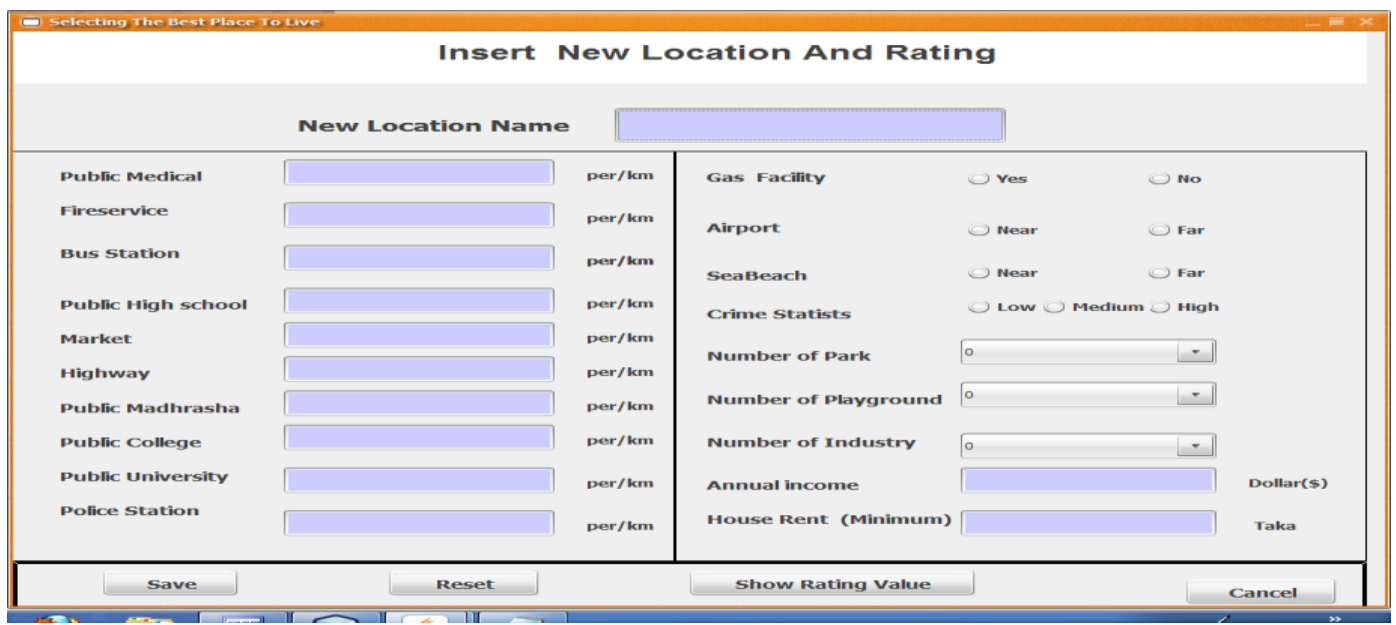

Figure 5: Rating Insert page

\section{4 . Rating Update page}

This is the link for update information. If we have done wrong data set in the table of database. Then we have used this page for update.

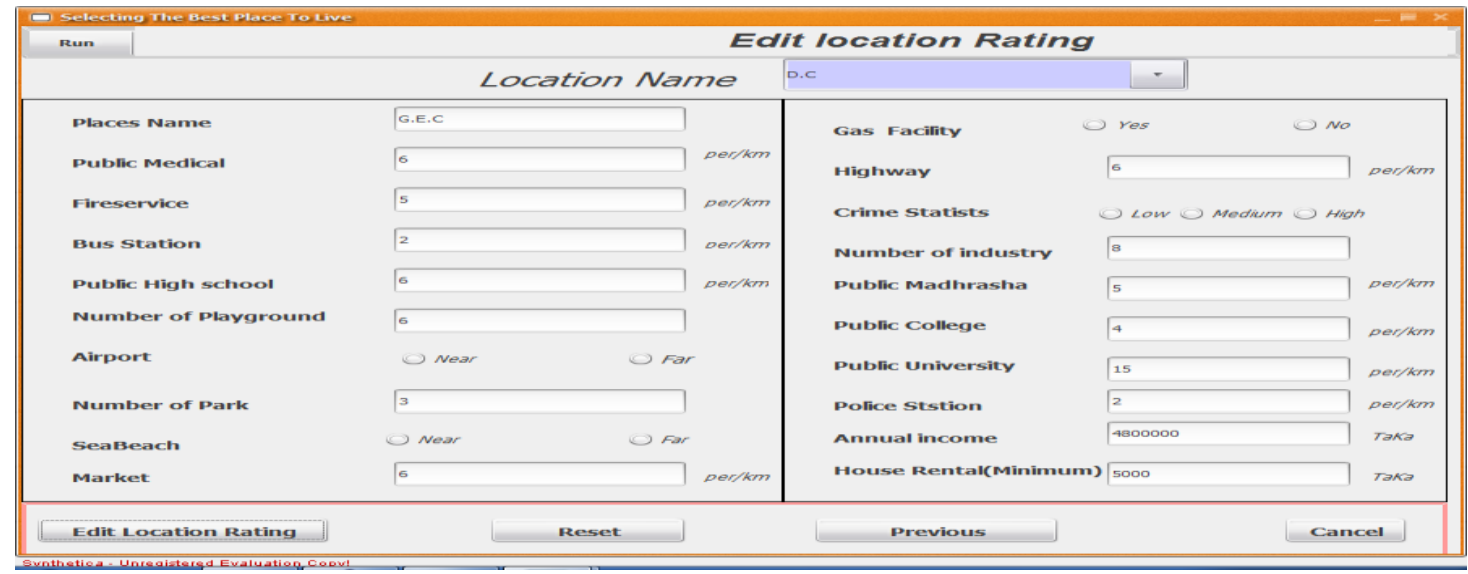

\section{Figure 6: Update Form to correction data}

\subsection{Delete Rating page}

We removed wrong data from the database table by this page.

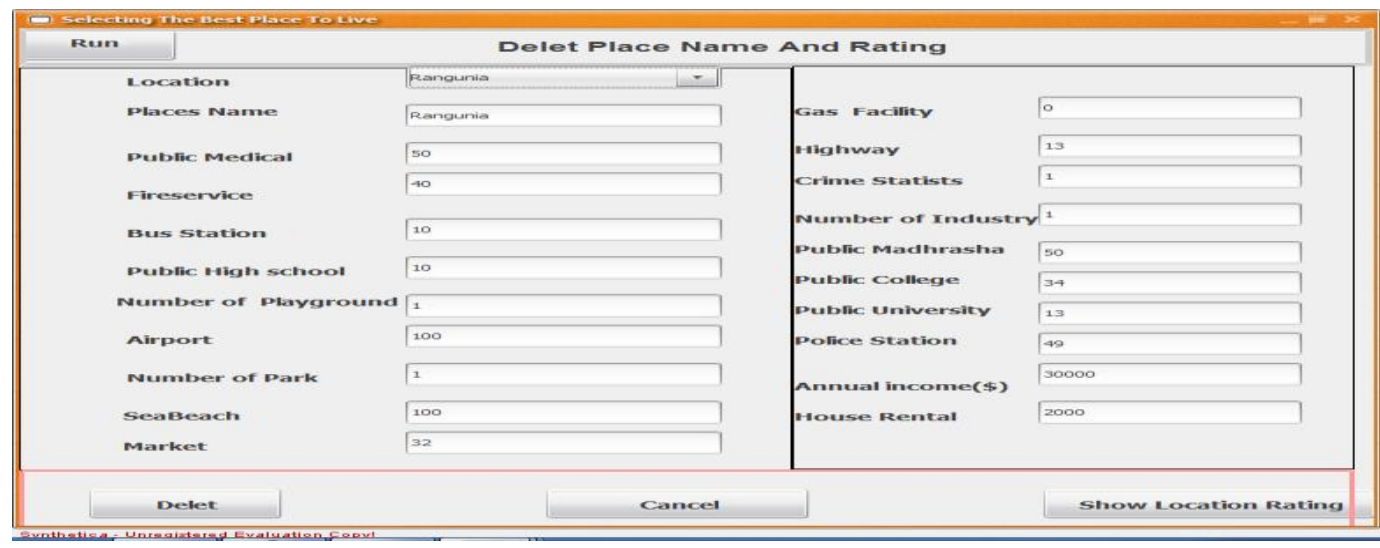

Figure 7: Delete rating page. 


\subsection{Search Result Page}

This page is used for searching the best location according to the factors of location. Then we will get final location. When Fill up every text field by the assigned weight and click search option then final location display by a message which is shown in the following figure
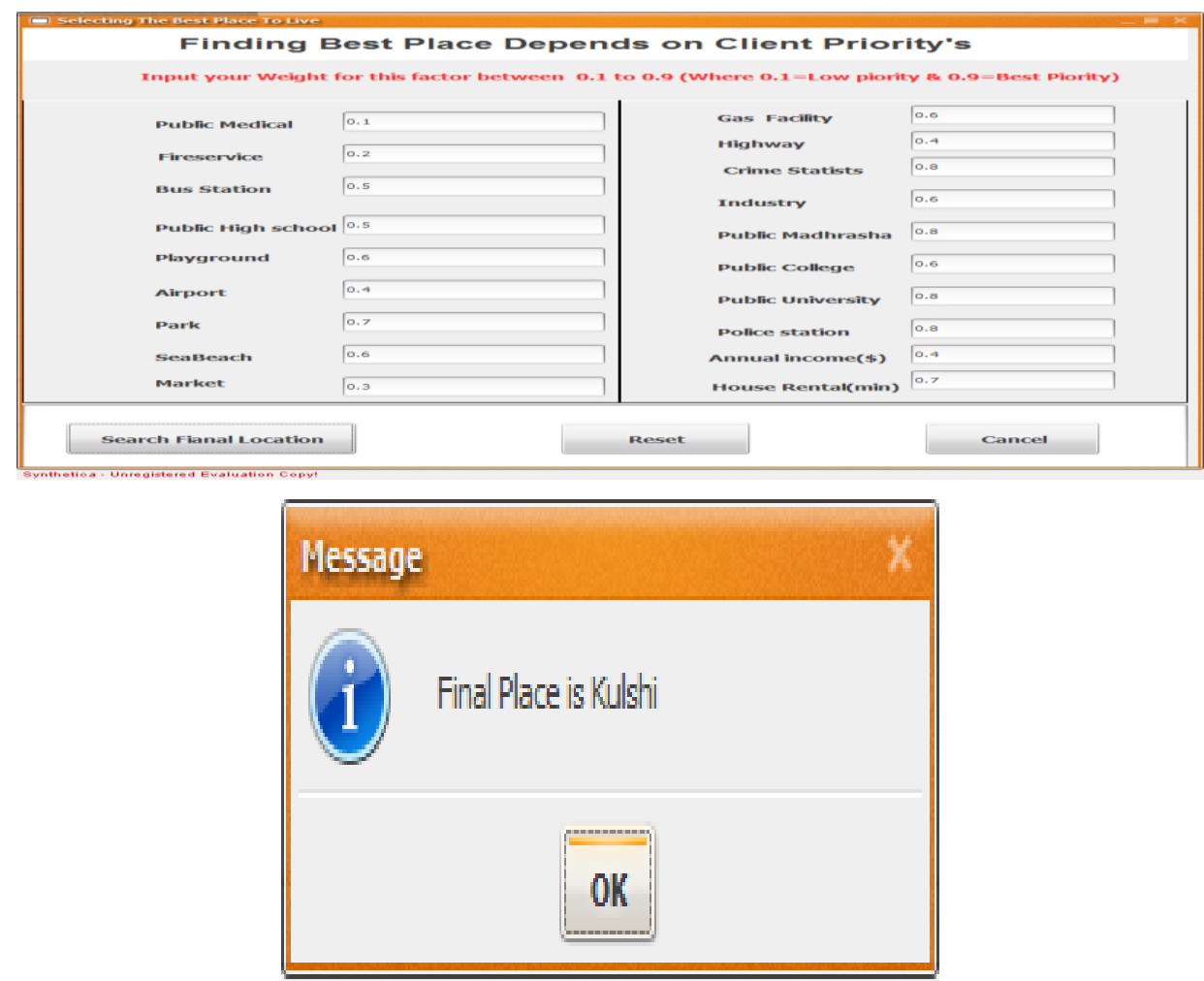

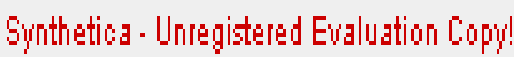

Figure 8: Search Result page and display result.

\section{CONCLUSION}

By this project any client searches a best location in Chittagong area based on multiple criteria. The methodology and application development illustrates the selection good places based on user desired places characteristics that ranks these area based on important factors. Here fifteen areas which are most developed area in Chittagong city. These areas are Agrabad CDA, Kulshi, Jamal Khan, Suganda Residence area, Nasirabad Hillview, Chandgaon Residence area, Cosmopoliton residence area, G.E.C area, Chawkbazar area, Halishahar residence area, New Market area, Airport area, Chittagong Cantonment area, Khalpholok residence area. Select which are expressed in a qualitative way in Chittagong area, the Implicit weighting scheme is an effective method. These areas are measurement by some importance criteria's. Such safety, Educational facilities, Gas availability, Include playground and park in these areas, etc. So I think this project helps easily finds a good location for accommodation for a client.

\section{FUTURE WORK}

This project work was done only one city area in Bangladesh. In future follow this project a researcher will be prepared for all cities in Bangladesh. Since the database of this project easily modifiable and storable so it is possible he web based system and huge city area data of all country are stored in database. Then all people search their best place.

\section{REFERENCES}

[1] Stefan Hajkowicz , Andrew Higgins "A comparison of multiple criteria analysis techniques for water resource management" European Journal of Operational Research 184 (2008) 255-265.

[2] Salem Chakhar "Enhancing Geographical Information Systems Capabilities with Multi-Criteria Evaluation Functions" Journal of Geographic Information and Decision Analysis2003, Vol. 7, No. 2, pp. 47 - 71 .

[3] Klaas De Brucker, Cathy Macharis , Alain Verbeke, "Multi-criteria analysis in transport project evaluation: an institutional approach" European Transport $\backslash$ Trasporti Europei n. 47 (2011): 3-24.

[4] Howard, A.F. "A critical look at multiple criteria decision making techniques with reference to forestry applications" Canadian Journal of Forest Research 21, $1649-1659$

[5] Figueira, J., Salvatore, G., Ehrgott, M. (Eds.) "Multiple Criteria Decision Analysis: State of the Art Surveys. Springer"New York, pp. 27-72.

[6] Anjali Awasthi, S.S. Chauhan, S.K. Goyal "A multicriteria decision making approach for location planning for urban distribution centers under uncertainty" Mathematical and Computer Modelling 53 (2011) 98109. 
[7] N. Kundakci, E .A Adali ,A Tusisik "Tourist Hotel Location Selection with Analytic Hierarchy Process" journal of life Economics. 10 April 2014. pp. 47-58.

[8] DAGDEVIREN, M., YAVUZ, S., KILINÇ, N, "Weapon selection using the AHP and TOPSIS methods under fuzzy environment, Expert Systems with Applications 36" (2009) 8143-8151.

[9] KAHRAMAN, C., CEBECI, U., RUAN, D., 2004, Multi-attribute comparison of catering service companies using fuzzy AHP: The case of Turkey, International Journal of Production Economics, 87, 171-184.

[10] VAIDYA, O., S., KUMAR, S. (2006), Analytic Hierarchy Process: An Overview of Applications, European Journal of Operational Research, 169, 1-29.

[11] HO, W., 2008, Integrated analytic hierarchy process and its applications - A literature review, European Journal of Operational Research 186, 211-228. 